\title{
GEOMETRIA, PETROGRAFIA E DEFORMAÇÃO DE CORPOS ULTRAMÁFICOS METAMORFISADOS DA REGIÃO DE SANTA RITA DE OURO PRETO, MG, BRASIL.
}

\author{
Leonardo Eustáquio da Silva Gonçalves ${ }^{1}$, João Cláudio Moreira de Oliveira Costa ${ }^{1}$, \\ Issamu Endo ${ }^{1}$, Hubert Mathias Peter Roeser ${ }^{2}$
}

\begin{abstract}
RESUMO: A região de Santa Rita de Ouro Preto é historicamente conhecida pelo artesanato em pedra-sabão, designação popular do esteatito, cujo conteúdo de talco é superior a $75 \%$ e é produto do metassomatismo de rochas ultramáficas peridotíticas. Assim, o estabelecimento da geometria externa dos corpos ultramáficos metamorfisados, de onde se extrai o esteatito, está diretamente relacionado ao melhor aproveitamento econômico dos mesmos. Um modelo inicialmente proposto de zoneamento litológico, de geometria externa circular, cuja diferenciação petrográfica do núcleo em direção à borda, reflete em um núcleo quimicamente menos modificado. No presente trabalho, tal zoneamento litológico em linhas gerais se mantem, com suaves modificações. Entretanto, quanto a sua morfologia, propõe-se, uma geometria assimétrica para os corpos ultramáficos metamorfisados encontrados na região de Santa Rita de Ouro Preto e arredores, uma vez que a geometria arrendondada desconsidera a ação de um campo de tensões. Por meio de mapeamento geológico, em escala 1:10.000, caracterizaram-se corpos com geometria na forma de pods, cuja associação com diques de anfibolito reflete as direções aproximadas, NE-SW, de um campo de tensões, uma vez que os pods apresentam alinhamento NW-SE. Esses corpos foram deformados e sua geometria, em mapa observada na forma de "diques", reflete, de fato, a direção principal de alongamento dos pods. Neste contexto, esse manuscrito visa fornecer subsídios para o melhor entendimento dos processos deformacionais ocorridos, da geometria e do posicionamento tectônico destas rochas.
\end{abstract}

Palavras-chave: geometria assimétrica, deformação, esteatito, Santa Rita de Ouro Preto, Quadrilátero Ferrífero.

\begin{abstract}
GEOMETRY, PETROGRAPHY AND DEFORMATION OF METAMORPHOSED ULTRAMAFIC BODIES FROM SANTA RITA DE OURO PRETO REGION, MG, BRASIL. The Santa Rita de Ouro Preto district is historically known for its handcraft using "soapstone", a popular rock with low stiffness due to its high talc percentage, upper $75 \mathrm{wt}$. \%. These rocks are named steatites and they are generated when ultramafic peridotites are submitted to metassomatic processes. Then, establishing the external geometry of the metamorphosed ultramafic bodies from which the soapstone is exploited, a better economical exploitation of those rocks could be attained. A proposed model based on lithological zoning with circular external geometry where there is a petrographic differentiation from the core to the rim with less chemical differentiation at the core. The lithological zoning is maintained in this work as previously proposed, with small restrictions. However, we propose an asymmetric geometry to ultramafic metamorphic bodies near the Santa Rita district and surrounding areas, once the rounded zoning model does not consider action of field stress. Through geological mapping (scale: 1:10,000) an external geometry of ultramafic metamorphic bodies known as pods were characterized. This feature has a common association with dikes of mafic metamorphic rocks, such as amphibolites; this suggests that a field stress acted during the formation of those bodies. The pods present an alignment in the NW-SE orientation which agrees with the general vergence of the field stress, approximately NE-SW. The ultramafic metamorphic bodies were deformed and their geometries are observed in map as dikes, but they reflect the main direction of pods elongation. In this sense, the new geometry model supplies information to the better understanding of deformational processes that occurred in the Santa Rita de Ouro Preto region. This will also help determine the geometry of the pods and how ultramafic metamorphic rocks are tectonically positioned.
\end{abstract}

Keywords: asymmetric geometry, strain, soapstone, Santa Rita de Ouro Preto district, Quadrilátero Ferrífero.

\section{INTRODUÇÃO}

As rochas ultramáficas metamorfisadas abordadas neste estudo são de extrema importância para a economia local do distrito de Santa Rita de Ouro Preto e arredores (Figura 1). Geologicamente, esta região se enquadra no domínio tectônico do sinclinal Dom Bosco, situado na porção meridional do Quadrilátero Ferrífero

1 - Departamento de Geologia - Escola de Minas - Universidade Federal de Ouro Preto - Campus Morro do Cruzeiro - Minas Gerais - Brasil - CEP 35400-000. Email: leonardo@degeo.ufop.br

2 - Departamento de Engenharia Ambiental - Escola de Minas - Universidade Federal de Ouro Preto - Campus Morro do Cruzeiro - Minas Gerais - Brasil - CEP 35400-000. 


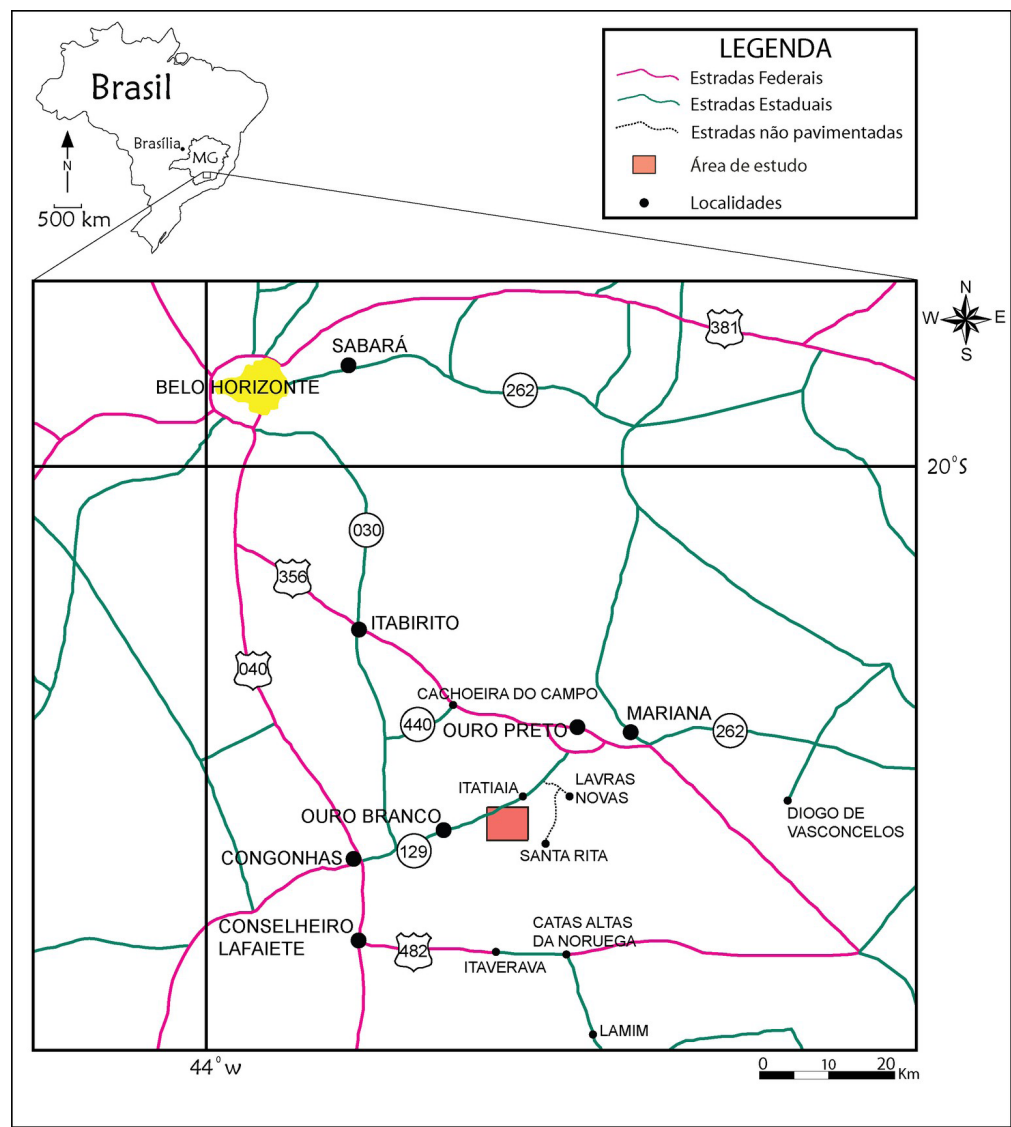

Figura 1 - Mapa de localização da área de estudo, modificado de IBGE - acesso em 2007.

(QFe). Os corpos ultramáficos metamorfisados, segundo Raposo (1991), se enquadram no domínio do Complexo Santo Antônio do Pirapetinga. Esse complexo é constituído por um conjunto de rochas arqueanas ultramáficas e máficas meta-morfisadas (serpentinitos, esteatitos, talco-xistos e anfibolitos) associadas a gnaisses tonalitotrondhjemíticos, sendo que de forma subordinada ocorrem rochas metapelíticas (xistos), formações ferríferas e quartzitos, que segundo este autor caracteriza o embasamento regional. A área de estudo, delimitada na figura 1, é apresentada em detalhe na figura 2, na qual pode se observar a região de ocorrência do Complexo Santo Antônio do Pirapetinga, a sudeste.

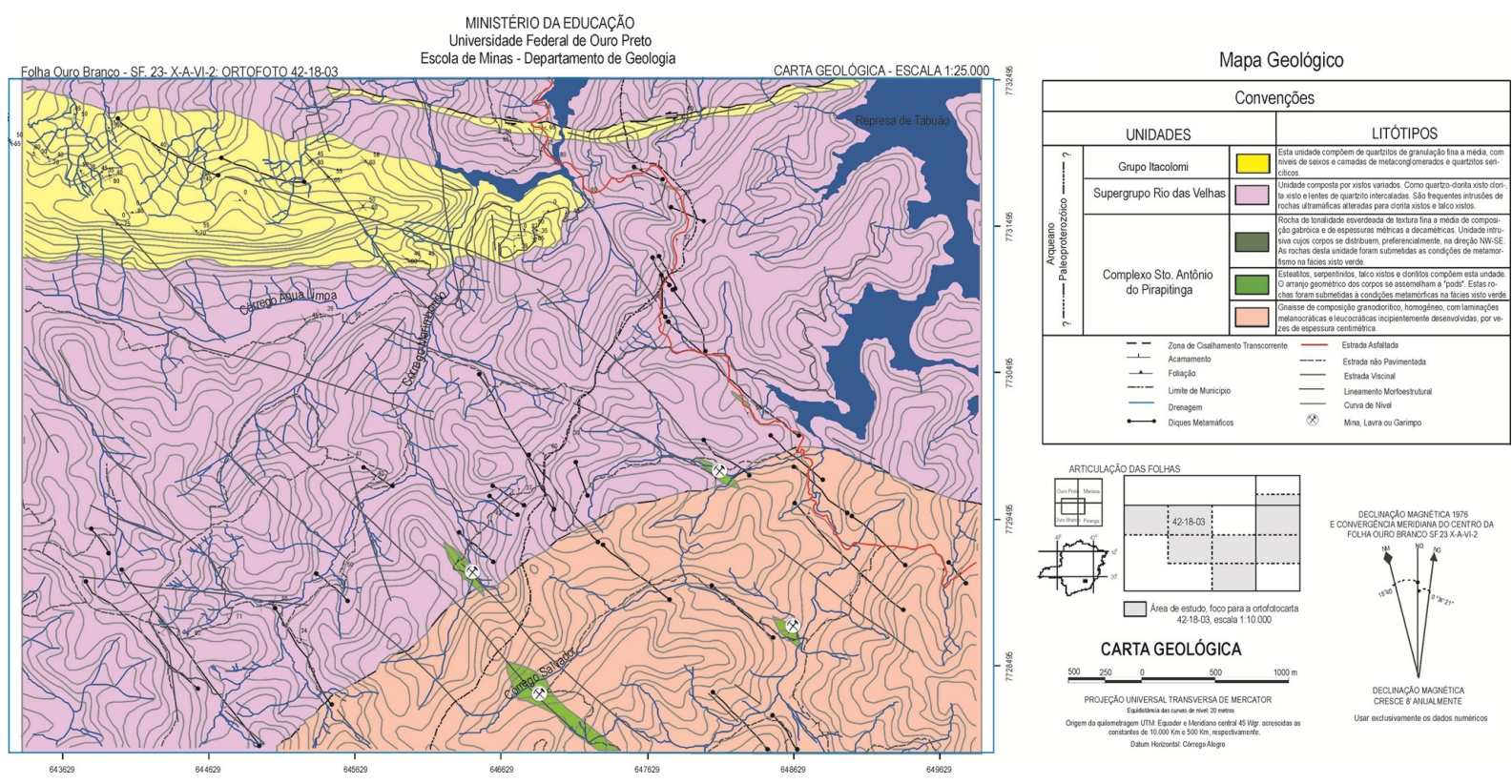

Figura 2 - Mapa geológico simplificado da porção meridional do Quadrilátero Ferrifero (modificado de Dorr 1969, Alkmim 1987, Almeida et al. 2002, Gonçalves \& Costa 2007). 
Para melhor entendimento da petrogênese das rochas ultramáficas metamorfisadas, trabalhos com caráter geoquímico e petrográfico têm sido realizados (Roeser et al. 1980, Jordt-Evangelista \& Silva 2005), entretanto aspectos estruturais e de deformação não são considerados. Assim, não se faz referência aos processos deformacionais aos quais estas rochas foram submetidas, possivelmente devido à alta plasticidade do esteatito, o que lhe confere complexo arranjo estrutural. Roeser (1979) propõe um zoneamento litológico para esses corpos, que se daria de maneira concêntrica e circular. No entanto, formas circulares são mais comuns como geometria externa de corpos de rochas ácidas e não são esperadas como geometria de corpos de caráter básico a ultrabásico. Propõem-se, então, uma geometria assimétrica para os corpos ultramáficos metamorfisados estudados, embora o zoneamento litológico, em linhas gerais se mantenha. A geometria assimétrica proposta se baseia em interpretações de fotografias aéreas e observações de campo e é de alta relevância para o desenvolvimento de futuros modelos prospectivos, visto que ainda não há um modelo estabelecido. Assim, a partir dos dados apresentados tem-se subsídios para estudos de viabilidade econômica desses corpos, embora não seja propósito deste trabalho indicar locais para futuros empreendimentos mineiros.

\section{METODOLOGIA}

A metodologia empregada neste trabalho constou de mapeamento geológico de detalhe, escala 1:10.000, com vistas à caracterização geral, principalmente no que se refere à geometria externa exibida pelos corpos ultramáficos metamorfisados. Tendo-se em mente o zoneamento litológico existente, proposto por Roeser (1979), foi escolhida uma pedreira, em atividade, próximo ao córrego Salvador (Figura 2). Tal escolha se deve ao fato da excelente exposição dos litotipos que compõem o zoneamento litológico, permitindo uma segura coleta de amostras ao longo deste zoneamento, do centro em direção à sua borda. Dessa forma, os cinco litotipos que formam o zoneamento dos corpos ultramáficos metamorfisados, apresentados em detalhe no item seguinte, foram amostrados e analisados por meio de lupa petrográfica e ao microscópico ótico.

\section{CARACTERÍSTICAS GERAIS DOS CORPOS ULTRAMÁFICOS METAMORFISADOS ESTUDADOS}

Os corpos ultramáficos metamorfisados variam de dimensões métricas a decamétricas e se encontram encaixados tectonicamente em xistos, anfibolitos e gnaisses. Pode-se observar uma enorme variedade de litotipos para estes corpos, sendo que, do centro em direção as rochas encaixantes, tem-se a seguinte disposição: serpentinito, seguido por serpentina-talco granofels, talco granofels (esteatito), anfibólio-talcoclorita granofels e mais externamente cloritito. Esse zoneamento difere daquele proposto por Roeser (1979), o qual, do centro em direção às rochas encaixantes, compõe-se de: serpentinito, esteatito maciço, carbonatotalco fels, anfibólio-talco fels e clorita fels. Tanto os esteatitos quanto os serpentinitos são rochas metamórficas derivadas de rochas ultramáficas, e sua geração está ligada à introdução de $\mathrm{H}_{2} \mathrm{O}$ no sistema, podendo haver também contribuições de $\mathrm{CO}_{2}$ e/ ou ainda troca de elementos químicos. Esta última caracterizada pelo contraste na composição química, verificado entre as rochas ultramáficas e as rochas encaixantes. Como estes processos de transformação podem ocorrer em conjunto nas rochas ultramáficas, é muito difícil separar geoquimicamente a influência de um, ou de outro.

Macroscopicamente, o serpentinito apresenta coloração esverdeada com presença de carbonato, este não efervesce a frio ao ataque de ácido clorídrico, portanto não se trata de calcita. Microscopicamente, este litotipo é composto essencialmente por agregados de serpentina fibrosa, possivelmente variedade crisotila. Orientações preferenciais não são observadas, o que caracteriza uma textura decussada (Figura 3 a-b) e implica que a rocha seja classificada como um serpentina granofels. Têm-se, ainda, cristais de carbonato, dispostos sobre a matriz da rocha. O serpentinatalco granofels é untuoso ao tato, e de coloração esbranquiçada a levemente acinzentada. Nota-se a presença de minerais relictos, como minerais aciculares, provavelmente "fantasmas" de anfibólios, e relictos de mineral de hábito romboédrico, provavelmente, cristais de carbonato arrancados. Ao microscópio ótico, o serpentina-talco granofels, conforme figura 3 (c-d), é composto de $65 \%$ em volume de talco, $25 \%$ de serpentina, $10 \%$ de carbonato e porcentagem traço de clorita. O talco granofels ocorre localmente e, por vezes, se associa à preenchimentos de veios ou fraturas, sendo composto por $95 \%$ de talco e os $5 \%$ restantes distribuídos entre clorita e carbonato (Figura 3 e-f). O litotipo caracterizado, em campo, como anfibólio-talco granofels, levemente deformado, cuja coloração é esbranquiçada, mostrou se tratar, ao microscópio ótico, de um anfibólio-talco-clorita granofels. A análise modal deste litotipo mostra composição de, aproximadamente, $50 \%$ em volume de clorita, $30 \%$ de talco e $20 \%$ de anfibólios. A textura característica dessa variedade de rocha ultramáfica metamorfisada é decussada (Figura 4 a-d). Por fim, localizado nas bordas dos corpos ultramáficos metamorfisados, tem-se o cloritito. De coloração esverdeada, este litotipo é composto de cristais de clorita, essencialmente magnesiana, os quais não apresentam orientação preferencial, o que, novamente, caracteriza uma textura decussada (Figura 4 e). Lamelas de talco são observadas e preenchem pequenas fraturas (Figura $4 \mathrm{f}$ ), possivelmente como produto de um evento hidrotermal tardio. A moda deste litotipo apresenta $95 \%$ de clorita e $5 \%$ de talco, classificado, portanto, como clorita granofels (e.g. Costa et al. 2007). 

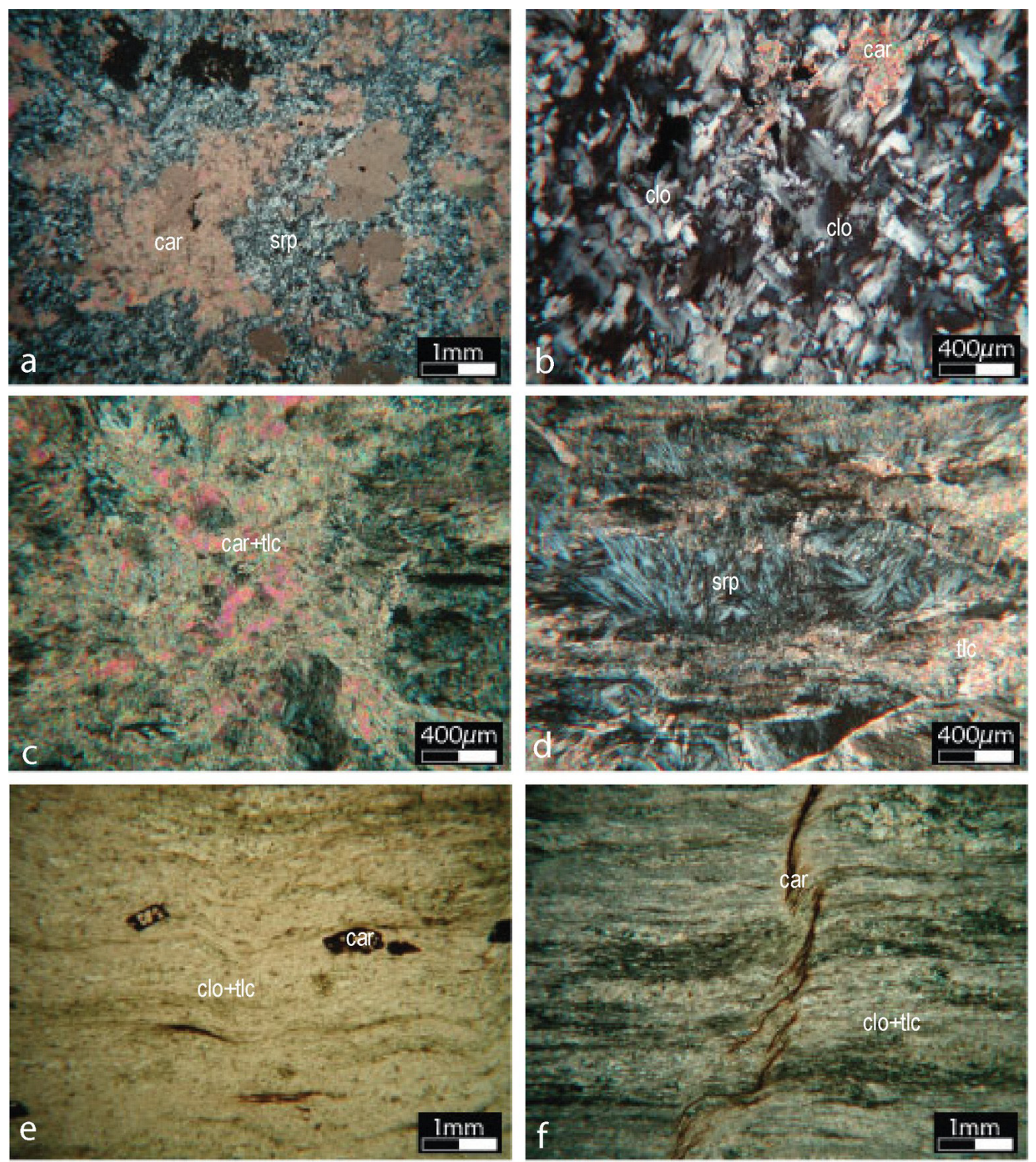

Figura 3 - Fotomicrografias das rochas ultramáficas metamorfisadas estudadas: a e b) Serpentinito, apresentando textura decussada, estágio inicial no desenvolvimento dos corpos ultramáficos metamorfisados; c-d, representam o segundo estágio do zoneamento. c) Carbonato (car), talco (tlc)

d) Serpentina (srp), talco (tlc); e-f) Talco (tlc), Clorita (clo), carbonato (car), no talco granofels, representam o terceiro estágio.

Em relação ao grau metamórfico, os corpos ultramáficos metamorfisados apresentam feições de metamorfismo que indicam condições de $\mathrm{Pe} \mathrm{T}$ da fácies metamórfica xisto verde, indicado pela paragênese mineral: clorita \pm serpentina \pm talco \pm tremolita \pm carbonato.

\section{GEOMETRIA EXTERNA DOS CORPOS ULTRAMÁFICOS METAMORFISADOS DE SANTA RITA}

Os corpos ultramáficos metamorfisados da região de Santa Rita de Ouro Preto e adjacências estão notoriamente deformados. É coerente, conforme dados estruturais (Figura 5), a hipótese que tal deformação esteja associada ao evento orogenético Brasiliano caracterizada no QFe (Alkmim \& Marshak 1998). Este evento, de vergência geral para $\mathrm{W}$, foi responsável pela geração de diversas estruturas na região, como zonas de cisalhamento, orientadas preferencialmente segundo a direção N-S e reativação de estruturas E-W e NW-SE com componente de movimento sinistral (Figura $6 \mathrm{a}-\mathrm{b}$ ).

A interpretação de fotografias áreas e ortofotos, a princípio sugerem uma forma tabular para os corpos ultramáficos metamorfisados, no entanto, quando observados em campo, os mesmos apresentam forma aproximada de corpos "amendoados", sigmoidais. Segundo Twiss \& Moores (1992), um corpo de geometria circular submetido a um campo de esforços tectônicos terá sua morfologia modificada e irá adquirir 

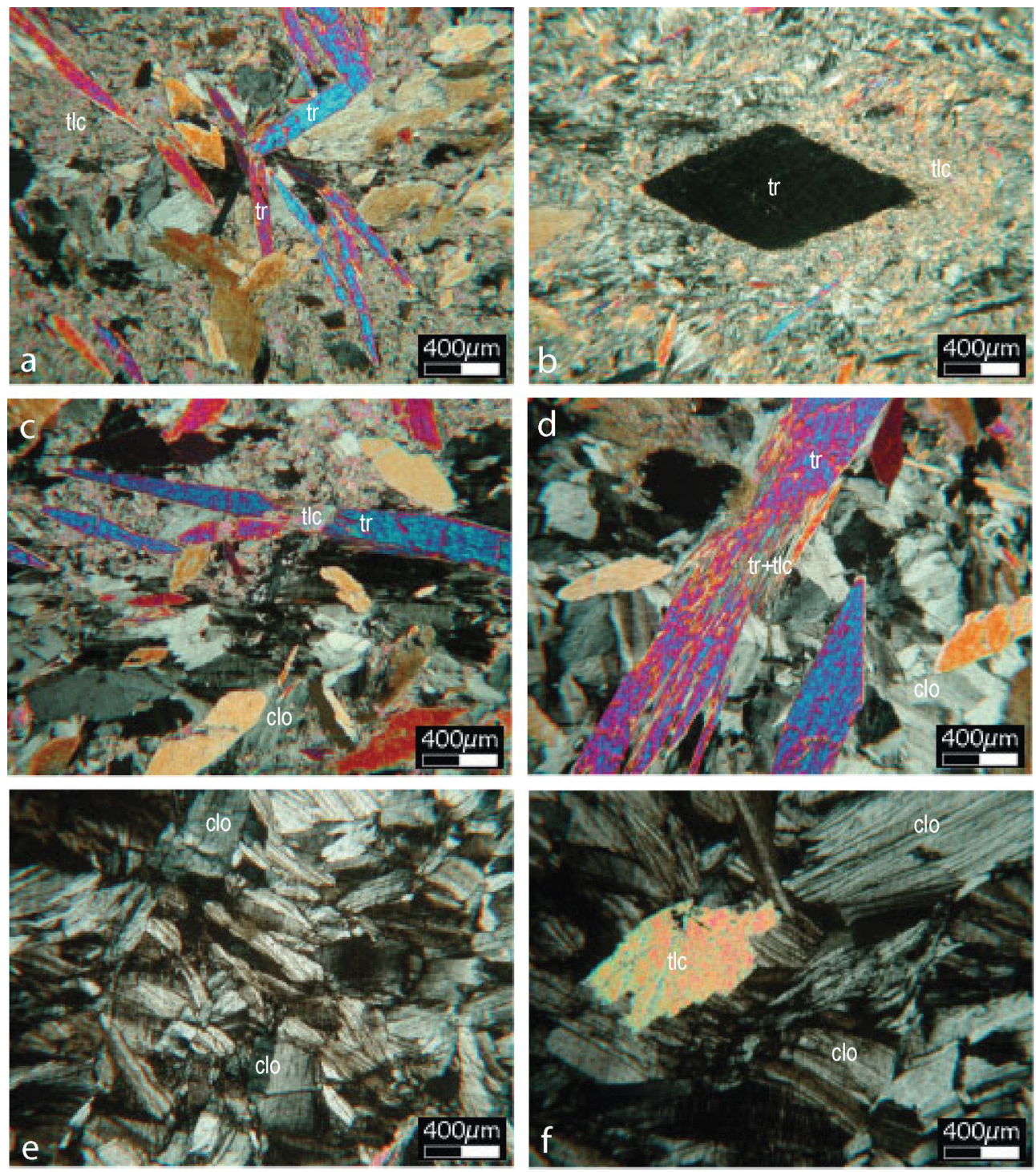

Figura 4-Fotomicrografias das rochas ultramáficas metamorfisadas estudadas: a-d) Cristais prismáticos de tremolita (tr), sem orientação preferencial, por vezes, substituidos por talco, representam o quarto estágio da evolução proposta para os corpos ultramáficos metamorfisados. Notam-se cristais de clorita (clo) magnesiana que compõe a matriz da rocha; e) Cloritito com textura decussada - Clorita (clo); f) Talco (tlc) em meio às cloritas (clo), as figuras e-f, representam o último estágio evolutivo dos corpos ultramáficos metamorfisados.

geometria elipsoidal, cujas razões axiais devem ser tão altas quanto maior for a magnitude da deformação. Considerando corpos inicialmente amendoados, a aplicação de um campo de tensões deve modificar sua geometria, tornando esses corpos mais alongados e com formatos sigmoidais, cuja assimetria, deve refletir a cinemática da deformação, em caso de deformações não-coaxiais.

Neste cenário, os sigmóides ou pods foram deformados e metamorfisados, o que culminou na mudança de sua geometria externa. Como conseqüências desta deformação, pode-se mencionar uma nítida foliação de borda, um novo arranjo geométrico e uma mineralogia com diferenças em relação à original. Como sugerido por Roeser et al. (1980), deve ter ocorrido intensa percolação de fluidos e injeção de $\mathrm{SiO}_{2}$, mantendo concomitantemente o espectro de elementos traços típicos para rochas ultramáficas (Cr, Ni, Co, V). Feições estas que caracterizam um processo metassomático ocorrido durante a transformação metamórfica, visto que estes corpos são relacionados à protólitos de rochas ultrabásicas (Roeser et al. 1980, Jordt-Evangelista \& Silva 2005). No entanto, análises geoquímicas são necessárias para que se confirme tal interpretação, o que não faz parte do escopo deste trabalho.

É neste contexto que se deve avaliar a geometria dos corpos estudados, sendo que conjugados ao campo de tensões houve ainda processos que auxiliaram na deformação dos corpos, como o acesso de fluidos e uma intensa granitogênese. Tal granitogêne é representada, em campo, por corpos de dimensões métricas muito intemperizados, não exibidos em mapa devido à escala de trabalho. Desta forma, propõe-se uma forma assimétrica, ilustrada pela figura 7, onde os esforços aplicados condicionariam não só a uma geometria distinta, mas também a uma nova mineralogia, coerente com o sentido das forças atuantes. 


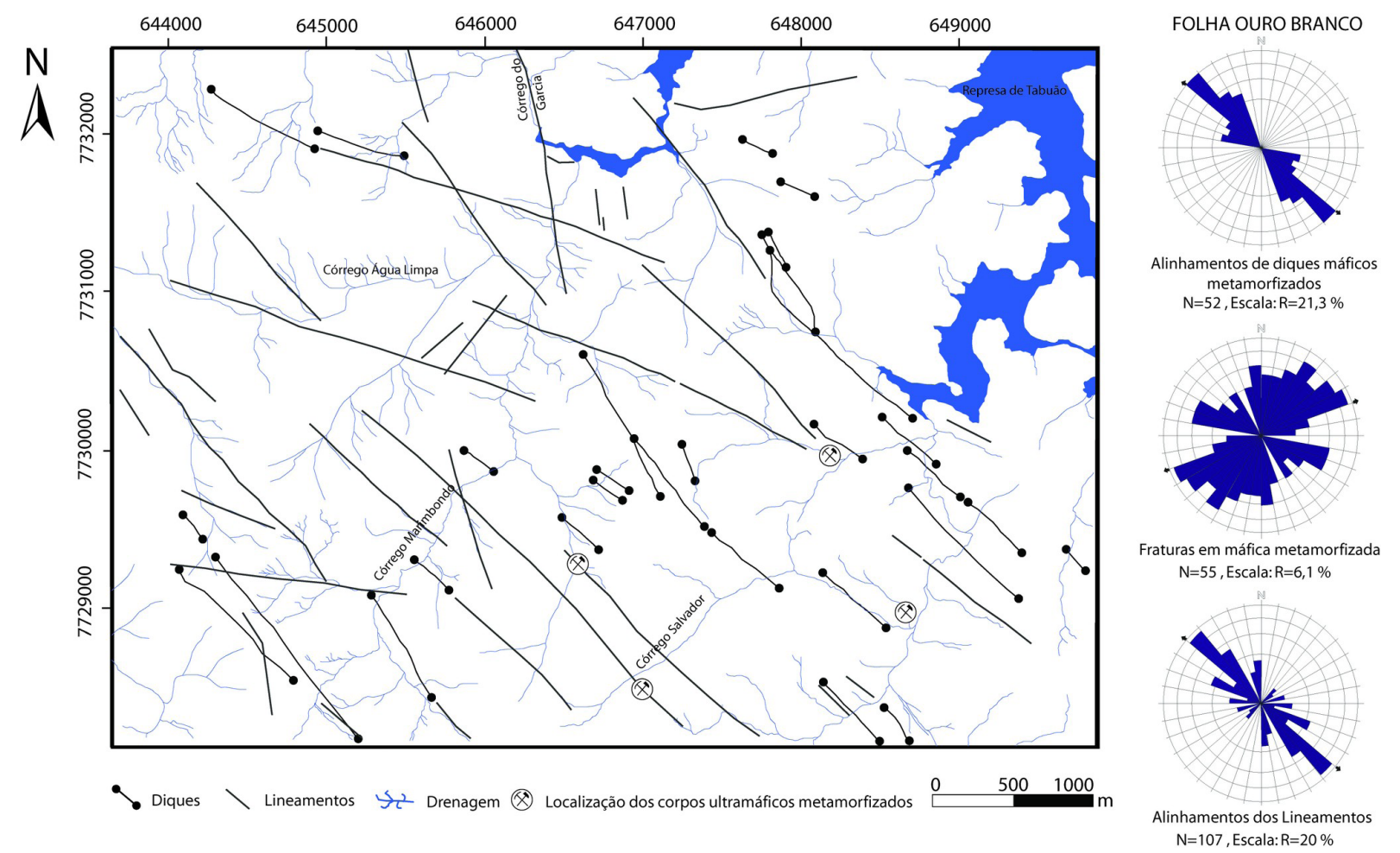

Figura 5 - Mapa mostrando o alinhamento dos lineamentos e diques observados na área de estudo, bem como diagramas de rosa representativos das direções preferenciais destas estruturas. Alinhamento preferencial de diques e lineamentos: N50W; direção preferencial das fraturas N70E (modificado de Gonçalves \& Costa 2007).
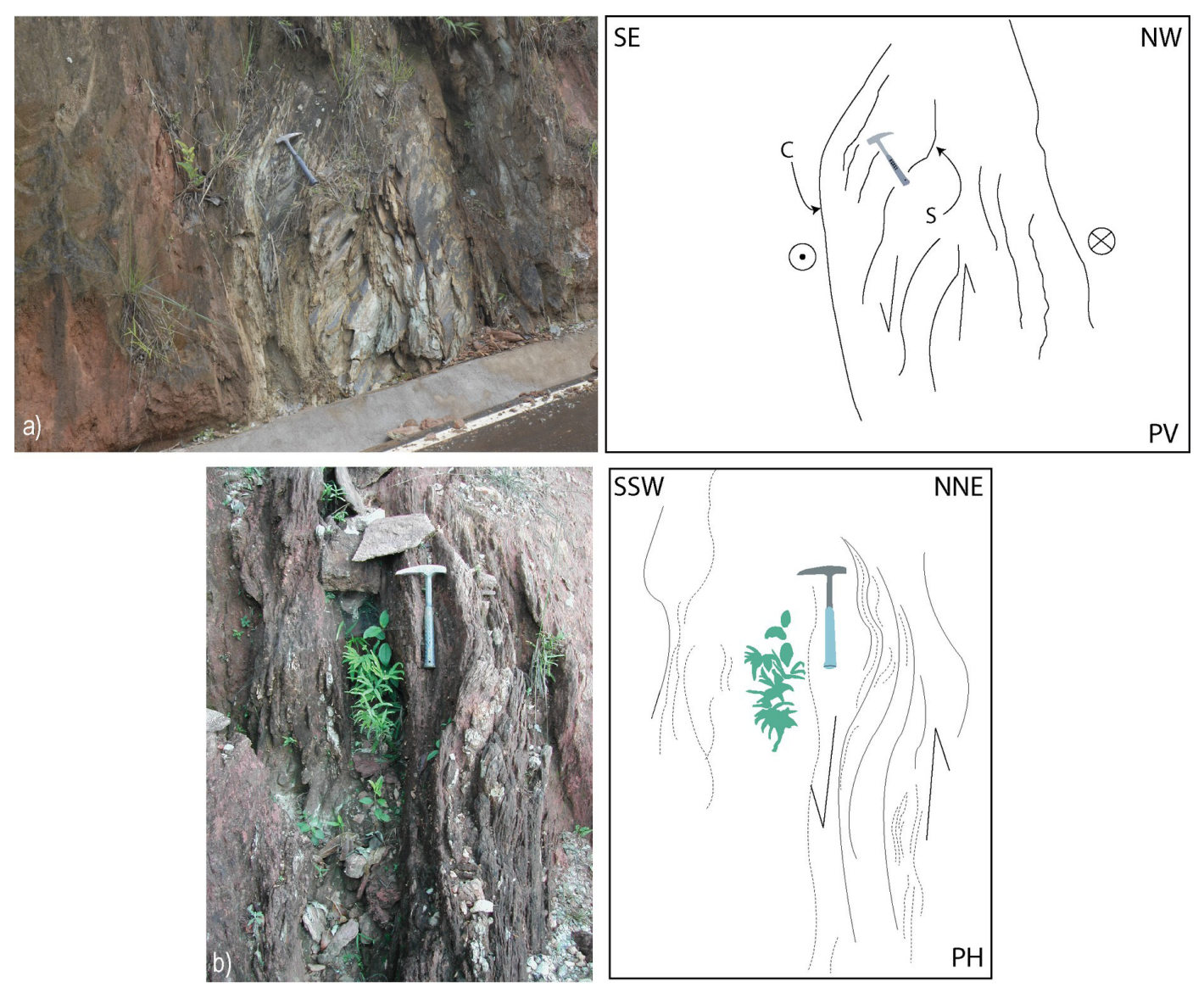

Figura 6 - a) Estrutura com geometria em sigmóide, cuja representação esquemática (PV-plano vertical) à direita indica cinemática reversa sinistral, $C=010 / 70 ; S=025 / 72$. b) Estrutura com morfologia em sigmóide, cuja representação esquemática (PH-plano horizontal) à direita indica novamente cinemática sinistral, atitude da foliação 020/80. 


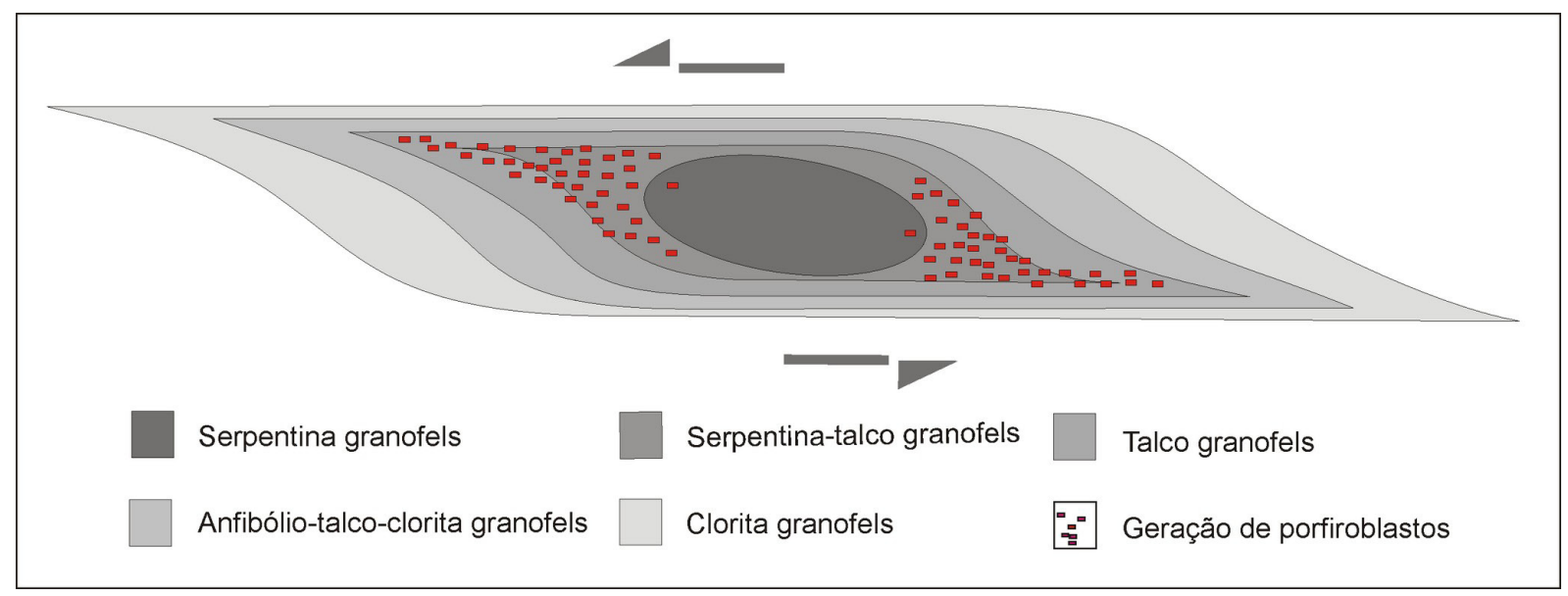

Figura 7 - Geometria esquemática das rochas ultramáficas metamorfisadas (modificado de Gonçalves \& Costa 2007).

Considerando-se que as fases fluidas migram para as regiões de alívio de pressão, os fluidos presentes durante o processo de deformação, tenderiam a se concentrar nas regiões de maior alongamento, mega "sombras de pressão" (Figura 7). Como o fluido do sistema é além de $\mathrm{H}_{2} \mathrm{O}$, rico em $\mathrm{CO}_{2}$ e outros complexos químicos resultantes das reações metassomáticas, é possível então apontar locais com maiores concentrações de minerais provenientes deste fluido, os quais estariam localizados na direção da tensão principal mínima, $\sigma 3$, indicado na figura 7 como local para a geração de porfiroblastos. Vale ressaltar que estas implicações são válidas independentemente da escala considerada. Dentro deste contexto, observa-se que todas as variedades de rochas ultramáficas metamorfisadas da área apresentam uma carbonatação generalizada, geralmente de dolomita, porém sabendo-se as zonas onde estes ocorrem com maior teor, é possível direcionar estudos de viabilidade econômica.

\section{ASPECTOS ECONÔMICOS}

Estas rochas constituem importante fonte de renda para as comunidades locais e sua extração já é algo bastante difundido na região. Dentre as variedades de ultramafitos metamorfisados, os esteatitos e os serpentinitos são os que implicam maior valor econômico agregado, sendo inclusive já lavrados.

Os esteatitos, por serem rochas macias e de fácil manipulação, são amplamente empregados no artesanato local. São rochas de tonalidade cinza claro a cinza escuro, da qual se pode extrair o mineral talco, que é um filossilicato hidratado de magnésio que constitui quase toda a massa da rocha. Devido à sua composição química, estrutura cristalina e textura, diferentes aplicações podem ser atribuídas ao talco, como a elaboração de cosméticos, tintas, cobertura de papel, inseticidas, borracha, fundente na indústria cerâmica, entre outros.

Os serpentinitos são rochas de tonalidade verde escuro a verde claro, de composição química rica em magnésio, constituídos predominantemente por minerais do grupo da serpentina. Algumas de suas características como uma maior resistência à abrasão e o fato de aceitarem polimento, permitem que essas rochas sejam utilizadas como rochas ornamentais. Elas podem ser empregadas ainda para a correção de solos a partir da produção de "pó de pedra", derivado com alto teor de $\mathrm{MgO}$.

Dentre os minerais do grupo da serpentina, há uma variedade com hábito fibroso, a crisotila, que assim como outros minerais fibrosos, é um dos materiais utilizados como amianto na indústria. Esse material possui grande flexibilidade e elevada resistência química, térmica e elétrica é utilizado em vários produtos comerciais, como por exemplo, caixas d'água, telhas, revestimentos à prova de fogo.

\section{DISCUSSÕES E CONCLUSÕES}

As informações obtidas neste estudo permitem as seguintes sugestões quanto aos aspectos dos corpos ultramáficos metamorfisados da região de Santa Rita de Ouro Preto:

A geometria na forma de pods proposta para os corpos ultramáficos metamorfisados de Santa Rita de Ouro Preto e adjacências, reflete o posicionamento geral de um campo de tensões de orientação NE-SW. A deformação responsável por tal geometria deve ser associada ao evento orogenético Brasiliano, de vergência geral para W no Quadrilátero Ferrífero e, cujo pico deformacional e metamórfico ocorreu por volta de $600 \mathrm{Ma}$.

A geometria assimétrica, na forma de um sigmóide, dos corpos ultramáficos metamorfisados reflete que os mesmos foram fortemente deformados e, que possivelmente, parte da modificação mineralógica ocorrida e substancial incremento no teor de $\mathrm{SiO}_{2}$, combinado com a perda de $\mathrm{MgO}$ (Roeser et al. 1980), deve ter ocorrido durante esta fase de deformação. Assim, a classificação inicial dos corpos como diques, reflete, de fato, a forma alongada dos mesmos devido à deformação a que foram submetidos. Além disso, devese considerar para o modelo de evolução uma intensa participação de fluidos no sistema.

Como sugerido por Jordt-Evangelista \& Silva 
(2005) para as rochas ultramáficas metamorfisadas da região de Lamim, a sul da região de estudo, admite-se um protólito ultrabásico para as rochas ultramáficas metamorfisadas de Santa Rita de Ouro Preto, pois mesmo com a mineralogia destes corpos bastante modificada, verifica-se uma afinidade ígnea para a origem dos mesmos.

Em relação à viabilidade econômica destes corpos, desde o século XVI, período do estilo arquitetônico Barroco, já se sabe da extração de "pedra-sabão" nesta região. No entanto, um estudo mais refinado acerca das estruturas e processos de migração de fluidos deve ser considerado, para que se possa obter um maior aproveitamento econômico destes litotipos.

\section{AGRADECIMENTOS}

Gostaríamos de manifestam nossos agradecimentos ao Departamento de Geologia da Escola de Minas de Ouro Preto pelas facilidades oferecidas para a realização dos trabalhos de campo e de laboratório durante a conclusão do curso de graduação dos dois primeiros autores. À professora Hanna Jordt-Evangelista pelo auxílio na descrição e interpretação das seções delgadas. Aos revisores Antônio Gilberto Costa e Gláucia Nascimento Queiroga, cujas críticas e sugestões contribuiram para o aprimoramento do manuscrito.

\section{REFERÊNCIAS BIBLIOGRÁFICAS}

ALKMIM F.F. 1987. Modelo deposicional para a seqüência de metassedimentos da Serra de Ouro Branco, Quadrilátero Ferrífero, Minas Gerais. In: Boletim da Sociedade Brasileira de Geologia. Minas Gerais: SBG-MG, 6:47-68.

ALKMIM F.F., MARSHAK S. 1998. Transamazonian Orogeny in the Southern São Francisco Craton Region Minas Gerais Brazil: evidence for Paleoproterozoic collision and collapse in the Quadrilátero Ferrífero. Precambrian Research, 90:29-58.

ALMEIDA L. G., ENDO I., CASTRO P. DE T. A., FONSECA M. A. 2002. Formação Estrada Real: Nova Unidade Litoestratigráfica do Supergrupo Minas, Quadrilátero Ferrífero, MG. In: Congresso Brasileiro de Geologia, 41, João Pessoa: SBG, Anais, p. 615.

COSTA J. C. M. DE O., GONÇALVES L. E. DA S., ENDO I. 2007. Considerações Petrogenéticas Sobre as Rochas Metaultramáficas de Santa Rita de Ouro Preto, MG, Brasil. In: Simpósio de Geologia do Sudeste, 10, Diamantina: SBG-MG, Anais, p. 82.

DORR J. VAN N. II. 2ND. 1969. Physiographic, stratigraphic and structural development of the Quadrilátero Ferrífero, Minas Gerais, Brazil. Washington: USGS/DNPM, 110 p. (Professional Paper 641-A).

GONÇALVES L. E. DA S., COSTA J. C. M. DE O. 2007. Estratigrafia e Geologia Estrutural da Porção Meridional do Quadrilátero Ferrifero, MG: ORTOFOTOCARTA 42-18-03 (Escala 1:10.000). Ouro Preto: Universidade Federal de Ouro Preto - UFOP, Monografia $\mathrm{N}^{0} 435,97 \mathrm{p}$.

JORDT-EVANGELISTA H., SILVA M. E. DA. 2005. Rochas metaultramáficas de Lamim, sul do Quadrilátero Ferrífero, MG: contribuição ao conhecimento do protólito da pedra-sabão. Revista da Escola de Minas, 58 (1):11-20.

RAPOSO F. O. (ORG.). 1991. Texto explicativo e mapas (geológico e metalogenético), escala 1:100.000. Rio Espera, Folha SF. 23-X-B-IV, Estado de Minas Gerais. Brasília: DNPM-CPRM: Programas Levantamentos Geológicos Básicos do Brasil PLGB. 200 p.

ROESER U. F. 1979. Mineralogisch, Petrographisch, Geochemische Untersuchungen von Ultrabasitkomplexen in Sudöstlichen Minas Gerais, Brasilien. Zellerfeld: T. U. Clausthal, Diplom Thesis, $190 \mathrm{p}$.
ROESER U. F., ROESER H. M. P., MUELLER G., TOBSCHALL H. J. 1980. Petrogênese dos Esteatitos do Sudeste do Quadrilátero Ferrífero. In: Congresso Brasileiro de Geologia, 31, Santa Catarina: SBG, Anais, 4:2230-2241.

TWISS R. J., MOORES E. M. 1992. Structural Geology. New York, W. H. Freeman and Company, 535 p. http://wwwibge.gov. br. Mapa rodoviário de Minas Gerais, Brasil. Disponível em: Instituto Brasileiro de Geografia e Estatística (IBGE). Acesso em: 15 junho 2007. 